\title{
The effect of exercise and improved physical fitness on basal metabolic rate
}

\author{
BY S. A. BINGHAM, G. R. GOLDBERG, W. A. COWARD, \\ A. M. PRENTICE AND J. H. CUMMINGS \\ MRC Dunn Clinical Nutrition Centre, 100 Tennis Court Road, Cambridge CB2 1QL
}

(Received 24 March 1988 - Accepted 6 October 1988)

\begin{abstract}
1. The suggestion that there is a sustained enhancement in metabolic rate after exercise was investigated during the course of a study in which six normal-weight volunteers (three men, three women) took part in a 9-week training programme. Baseline values were assessed in a 3-5 week control period of minimal activity before training. At the end of the study the subjects were capable of running for $1 \mathrm{~h} / \mathrm{d}, 5 \mathrm{~d} /$ week.

2. Throughout the entire study the subjects were maintained on a constant diet. Measurement of energy expenditure by the doubly-labelled water $\left({ }^{2} \mathrm{H}_{2}{ }^{18} \mathrm{O}\right)$ method showed that the subjects had an energy imbalance of $+3 \%$ in the control and $-20 \%$ at the end of the training period. The subjects were in positive $(1 \cdot 1(\mathrm{SE} 0 \cdot 2) \mathrm{g})$ nitrogen balance in the second week of the control, and in negative $(-0.6$ (SE 0.3$) \mathrm{g}$ ) $\mathrm{N}$ balance in the last week of the exercise period.
\end{abstract}

3. Over the course of the study maximum oxygen consumption $\left(V_{o_{\text {gas }}}\right)$ and high-density-lipoproteincholesterol levels increased by $30 \%$. Heart rate at rest and when performing a standard step test fell significantly.

4. Body composition was assessed weekly by ${ }^{40} \mathrm{~K}$ counting and skinfold thickness measurements, in addition to ${ }^{2} \mathrm{H}_{2}$ dilution at the beginning and end of the study. Fat-free mass was apparently gained in the early phases of the study, but there was lack of agreement between the different methods of assessing body composition. Changes in body-weight were not significant.

5. Basal metabolic rate (BMR), overnight metabolic rate (OMR) and sleeping metabolic rate (SMR) were measured on three occasions: in the control period, and the beginning and end of the training periods. Average BMR in the control period was 5.91 (SE 0.39) $\mathrm{MJ} / 24 \mathrm{~h}$ and was not changed with activity. There were no changes in OMR (5.71 (SE 0.27) MJ/24 h in the control) nor in SMR (5.18 (sE 0.27) MJ/24 h in the control), nor in BMR, OMR or SMR when expressed per $\mathrm{kg}$ body-weight, or per $\mathrm{kg}$ fat-free mass.

6. These results do not support the suggestion that there is a sustained increase in BMR following exercise that can usefully assist in weight-loss programmes.

After exercise basal metabolic rate (BMR) is said to remain elevated for up to $48 \mathrm{~h}$ (Margaria et al. 1933; Edwards et al. 1935; Passmore \& Johnson, 1960). This observation is part of the reason for advocating programmes of weight control by means of exercise alone (Cannon \& Einzig, 1983). However, there have been no well-controlled long-term studies of the effect of exercise on metabolic rate in human beings in which diet was also taken into account. We have therefore determined the effects of a 2-month training programme which led to improved physical fitness on BMR, body composition, and total energy expenditure (TEE) in healthy subjects. In order to separate the effects of varying food intake from that of the exercise, diet was maintained at a constant level throughout the entire study.

\section{METHODS}

Protocol

Six healthy volunteers, three women and three men, aged $24-33$ years, were studied initially for 3-5 weeks, whilst undertaking only minimal activity (control), followed by a 9-week training programme (high activity). All were people with normally sedentary occupations who did not exercise or play sport on a regular basis. They were invited to participate after a satisfactory medical examination, and giving their informed consent to the protocol 
which had been approved by the Ethical Committee of the Dunn Nutrition Unit. A break between the control and training periods was permitted, but throughout the rest of the 3month study the subjects lived in the metabolism suite of the Dunn Clinical Nutrition Centre, where the training programme could be closely supervised, body composition assessed, urine and faecal collections made, and a constant diet provided. BMR was measured in the control period, and in the early and final stages of the training period. Total energy expenditure, maximum oxygen consumption $\left(V_{\mathrm{o}_{\text {max }}}\right)$ and other responses to exercise were also measured. Two subjects were studied from July to November 1985, and four subjects from February to July 1986.

\section{Diet}

A standardized diet containing normal food was provided for the study, comprising $34 \%$ energy as fat, $51 \%$ as carbohydrate, $14 \%$ as protein, and $22 \mathrm{~g}$ dietary fibre (Paul \& Southgate, 1978). A $4 \mathrm{~d}$ rotating menu was designed, having a coefficient of variation in overall composition of less than $1 \%$ amongst the $4 \mathrm{~d}$. Subjects were allowed variations from the standard menu to cater for particular likes and dislikes, but no food or drink that was not part of the menu and provided by the Unit was permitted, apart from water. Duplicate diets for each subject were prepared at the beginning and end of the study and homogenized. Portions were stored at $-20^{\circ}$, before being freeze-dried and later analyzed.

Within the first week of the study, BMR was measured (see p. 157) and the energy content of each subject's diet was then adjusted relative to the BMR, using butter, sucrose, cream and meat, to maintain or achieve a slight gain in body-weight. After the first week no change in diet was made for the rest of the study.

\section{Activity levels and training schedule (Table 1)}

Baseline levels were monitored in the 3-5 week control period, during which time the subjects continued their normal life (within the limits of the study protocol) except that only light activities were permitted. No more than 15 min walking outside per day was allowed, otherwise a taxi or unit car was used for transport. No other exercise such as cycling or sport was permitted. The control period lasted 3 weeks for the first two subjects, but was extended to 4-5 weeks for the remaining four in order to improve the precision of the baseline measurements and (in the women) to take account of possible variations due to the menstrual cycle.

In the following 9 weeks the subjects were allowed unlimited walking, and to return to their usual means of transport, such as cycling. A planning training schedule was followed, in which the time spent jogging each day was gradually increased (Table 1), so that by the end of the study all subjects were capable of jogging for $1 \mathrm{~h} / \mathrm{d}, 5 \mathrm{~d} /$ week. Training periods were preceded by 5-10 min of isometric exercises, and were directly supervised by one of the authors (S. B.) who participated in the training schedule for subjects nos. 3 and 4. Jogging on uneven surfaces was avoided and running shoes were provided by the Unit. No other running or similar sport such as tennis or football was permitted, but cycling or swimming was allowed in addition to the schedule. In the event of injuries, subjects maintained their level of fitness using a bicycle ergometer (Monark, Sweden), the load being adjusted to maintain heart rate at approximately 140 beats/min.

Subjects kept detailed weekly diaries of all activities (to the nearest minute) in the last week of the control, and in weeks 2,3 or 4 , and week 9 of the high-activity period. A daily record of jogging or cycling was kept throughout.

\section{Metabolic rates}

Metabolic rate was measured by whole-body indirect calorimetry (Murgatroyd et al. 1985) within the first week of the control period and in weeks 3-5 and 8-9 of the high-activity 
Table 1. Training programme for six healthy volunteers participating in the study

\begin{tabular}{cc}
\hline $\begin{array}{c}\text { High-activity period: } \\
\text { week no. }\end{array}$ & Daily schedule* \\
\hline 1 & 1 h of 5 min walking. \\
5 min jogging, \\
5 min rest \\
2 & 1 h of 10 min jogging, \\
5 min rest \\
3 & 15 min jogging \\
4 & $20-25$ min jogging \\
5 & $30-35$ min jogging \\
6 & $40-45$ min jogging \\
7 & $45-55$ min jogging \\
89 & 60 min jogging \\
\hline
\end{tabular}

*Values represent $\min / \mathrm{d}, 5 \mathrm{~d} /$ week.

period. Subjects slept in the calorimeter overnight. Overnight metabolic rate (OMR) was defined as the period from 23.30-08.00 hours, and sleeping metabolic rate (SMR) as the lowest continuous 60 min period recorded during this time. BMR was measured over $1 \mathrm{~h}$ (08.00-09.00 hours) immediately on walking, when subjects were at complete rest, $13 \mathrm{~h}$ post-absorptive and at $26^{\circ}$. In a separate study the coefficient of variation for repeated measurements was $1.9 \%$ (Prentice et al. 1989).

\section{$\mathrm{V}_{\mathrm{O}_{2} \text { max }}$ and heart rate}

$\left(V_{\mathrm{O}_{2} \max }\right)$ was assessed on a treadmill on two consecutive occasions at the end of the control period, and once on completion of the training schedule, using a modified Bruce procedure (Bruce \& McDonough, 1969).

Heart rate was monitored, using a Datascope 861 heart-rate meter, in response to a standardized step-test carried out by all the volunteers at weekly intervals during the highactivity period. Subjects stepped for $3 \mathrm{~min}$ at 15,20,25, 30 and 32 cycles/min on and off a $280 \mathrm{~mm}$ step in time with a metronome. Heart rate was measured during the last $10 \mathrm{~s}$ of each 3 min stepping cycle and at $30 \mathrm{~s}$ intervals for $3 \mathrm{~min}$ standing at rest after completion of the test.

Resting pulse rates and blood pressures were taken weekly, with the subjects sitting in bed before rising.

\section{Body composition}

The subjects weighed themselves daily immediately after rising, always in the same clothes, using a beam balance accurate to $50 \mathrm{~g}$ (CMS, London). Fat-free mass was assessed from ${ }^{40} \mathrm{~K}$ measured weekly in a two-crystal detector whole-body counter (NE 8102; Nuclear Enterprises Ltd) for $4000 \mathrm{~s} .{ }^{40} \mathrm{~K}$ counts were corrected for the morphology of the subjects, using a quadratic equation derived from studies of counts after injections of known amounts of ${ }^{42} \mathrm{~K}$ (Szaz, Parkinson, Cole and Coward, personal communication). The calculated total body $\mathrm{K}$ was converted to fat-free mass assuming a value of $68.1 \mathrm{mmol}$ $\mathrm{K} / \mathrm{kg}$ fat-free mass in men, and $64.2 \mathrm{mmol} \mathrm{K} / \mathrm{kg}$ fat-free mass in women (Forbes \& Bruining, 1976).

Skinfold thickness was measured at four sites every week with a Harpenden Caliper (Holtain Ltd, Crymmych), and percentage body fat calculated using the equations of Durnin \& Womersley (1974). Total body water was assessed in the control period and during weeks 8-9 by an oral dose of ${ }^{2} \mathrm{H}_{2} \mathrm{O}, 0.05 \mathrm{~g} / \mathrm{kg}$, on each occasion (see p. 158). Body 
fat was calculated from total body water assuming fat-free mass has a water content of $73 \%$.

\section{Energy expenditure}

TEE was measured by the doubly-labelled water method in the control period and during weeks 8-9. After the collection of a pre-dose urine sample, fasted subjects received oral doses of $0.05 \mathrm{~g}^{2} \mathrm{H}_{2} \mathrm{O}$ and $0.15 \mathrm{~g} \mathrm{H}_{2}{ }^{18} \mathrm{O} / \mathrm{kg}$ body-weight. Urine samples were collected at $4 \mathrm{~h}$, for the rest of the first day, and each morning for the next $13 \mathrm{~d}$. No food or drink was allowed during the $4 \mathrm{~h}$ equilibration period. Samples were stored at $-20^{\circ}$ until analysed.

Isotopic enrichment in pre- and post-dose samples was measured using an Aqua-Sira dual mass spectrometer (V-G Isogas, Middlewich, Cheshire). This system (described elsewhere by Barrie \& Coward, 1985) measures ${ }^{2} \mathrm{HH}:{ }^{1} \mathrm{H}^{1} \mathrm{H}$ ratios following the reduction of water samples to $\mathrm{H}_{2}$ gas, and $\mathrm{H}_{2}{ }^{16} \mathrm{O}: \mathrm{H}_{2}{ }^{18} \mathrm{O}$ ratios in water vapour directly let into the mass spectrometer. Three samples collected on the first day between 4 and $10 \mathrm{~h}$ after the dose and the subsequent single daily samples were measured.

Rate constants for ${ }^{2} \mathrm{H}$ and ${ }^{18} \mathrm{O}$ disappearance ( $K_{\mathrm{d}}$ and $K_{\mathrm{o}}$ respectively) were computed using a curve-fitting program (Feldman, 1977) applied to sample enrichment minus predose values. This procedure is equivalent to the customary log-transformation linearregression method. Zero-time distribution space for each isotope was calculated from zerotime isotope-enrichment values, using the equations derived by Halliday \& Miller (1977).

Calculation of carbon dioxide output rates then followed the procedures described by Coward \& Prentice (1985) and Coward et al. (1985). It was assumed that $40 \%$ of water loss was fractionated and ${ }^{2} \mathrm{H}$ and ${ }^{18} \mathrm{O}$ fractionation factors in water losses were 0.93 and 0.99 respectively. A factor of 1.04 was applied for fractionation effects in $\mathrm{CO}_{2}$ losses. No corrections were made to allow for total body-water changes in the measurement period.

Conversion of the estimates for $\mathrm{CO}_{2}$ production into values for energy expenditure was made by assuming that average respiratory quotient (RQ) during the experimental period was equivalent to the computed 'dietary RQ' (Black et al. 1986). Modifications to the 'dietary RQ' - subject RQ equivalence consequent on the storage or mobilization of nutrients were ignored.

A discussion of the significance of the various assumptions made in the entire methodology has been published previously (Coward et al. 1986).

\section{Metabolizable energy and nitrogen balance}

Faecal and urine collections ( $7 \mathrm{~d}$ ) were made in weeks $2-4$ of the control period and weeks 2-4 and 9 of the high-activity period. The completeness of the faecal collections was assessed by the radio-opaque-marker technique (Cummings et al. 1976), the subjects taking ten radio-opaque marker pellets in capsules with meals, three times daily. After weighing and X-raying the specimens to determine marker content, the number of markers recovered was compared with the numbers given. The stools were freeze-dried and the marker content of each stool was used to calculate marker-corrected dry faecal weight. The $7 \mathrm{~d}$ samples were pooled and ground using a Retsch agate mortar.

The completeness of the urine collections was assessed by comparison of urine recovery of oral doses of three $80 \mathrm{mg}$ tablets of $p$-aminobenzoic acid (PABA), the PABA check test (Bingham \& Cummings, 1983). The subjects collected all urine into 2-litre plastic containers containing $5 \mathrm{~g}$ boric acid as preservative. The volume was measured and portions frozen at $-20^{\circ}$ before analysis. Collections containing less than $90 \%$ of the oral doses of PABA were omitted from subsequent analysis. 
Table 2. Characteristics of volunteers participating in the study

\begin{tabular}{|c|c|c|c|c|c|c|c|}
\hline $\begin{array}{l}\text { Subject } \\
\text { no. }\end{array}$ & Sex & $\begin{array}{c}\text { Age } \\
\text { (years) }\end{array}$ & $\begin{array}{l}\text { Height (H) } \\
\text { (m) }\end{array}$ & $\begin{array}{r}\mathrm{Wt} \\
(\mathrm{kg})\end{array}$ & $\begin{array}{c}\text { BMI } \\
\left(\mathbf{W t} / \mathbf{H}^{2}\right)\end{array}$ & Occupation & Nationality \\
\hline 1 & $a^{\pi}$ & 33 & $1 \cdot 71$ & $64 \cdot 5$ & $22 \cdot 1$ & $\begin{array}{l}\text { Postgraduate } \\
\text { veterinary student }\end{array}$ & Sri Lankan \\
\hline 2 & $q$ & 29 & $1 \cdot 50$ & $51 \cdot 0$ & $22 \cdot 7$ & $\begin{array}{l}\text { Postgraduate } \\
\text { veterinary student }\end{array}$ & Sri Lankan \\
\hline 3 & $a$ & 29 & 1.83 & $67 \cdot 0$ & $20 \cdot 0$ & Computer programmer & British \\
\hline 4 & $q$ & 27 & 1.63 & $68 \cdot 5$ & 25.8 & Receptionist & British \\
\hline 5 & $3^{3}$ & 33 & 1.73 & $64 \cdot 0$ & $21 \cdot 4$ & Physicist & British \\
\hline 6 & q & 24 & 1.69 & $58 \cdot 5$ & 20.5 & Language student & Spanish \\
\hline
\end{tabular}

BMI, body mass index.

The diets, faecal and urine samples were analysed for total $\mathrm{N}$ using the Kjeldahl Kjeltec technique. Total energy in the diet and faecal samples was measured by bomb calorimetry using an adiabatic Gallenkamp bomb calorimeter. Metabolizable energy was calculated as the difference between the gross energy of the diet and marker-corrected faecal energy, with allowance for the $24 \mathrm{~h} \mathrm{~N}$ content of the urine samples (Passmore \& Eastwood, 1986). N balance was corrected for skin losses with different levels of activity as described previously (Bingham \& Cummings, 1985).

\section{General methods and statistics}

Early-morning fasting blood was taken on the last day of the control period, in week 4 or 5 of the activity period, and on the last day of the activity period. The plasma was stored at $-20^{\circ}$ before high-density lipoprotein (HDL) and total cholesterol measurements (Lopes-Virella et al. 1977; Slikers, 1977). Urinary, dietary and faecal K was measured by flame photometry (International Laboratories 243), the diets and faeces being ashed and dissolved in $10 \mathrm{M}$-hydrochloric acid before analysis. Urinary creatinine was measured using alkaline picrate (Cobas Bio; Roche Diagnostics), and urine urea by the Bertholet reaction (Sigma diagnostic procedure no. 640).

All results are expressed as means (with standard errors). Significance of differences was assessed by paired $t$ tests unless otherwise stated.

\section{RESULTS \\ General}

The heights, ages, occupations and weights at the beginning of the study of the six subjects studied are shown in Table 2 . Subject no. 4 was slightly overweight (body mass index $>25$ ), but all other subjects were of normal weight for their height. All subjects were healthy. Subject no. 1 smoked ten cigarettes/d. None of the female subjects were taking the contraceptive pill.

Gross, metabolizable and calculated energy contents of the diets are shown in Table 3. The energy content calculated from food tables overestimated metabolizable energy by 0.36 (SE 0.08) MJ $/ 24 \mathrm{~h}$. The ratio, metabolizable energy: first BMR measurement, was 1.61 (SE 0.11) (Table 3). There were no significant differences between results from the duplicate diets taken at the beginning of the study compared with those taken at the end $(0 \cdot 2$ (SE $0 \cdot 1)$ $\mathrm{MJ}$ differences in gross energy, 0.2 (SE 0.2 ) $\mathrm{g}$ differences in $\mathrm{N}$ content). Dietary $\mathrm{K}$ was also overestimated by calculation from food tables by $9 \%$. The mean calculated intake was 73 
Table 3. Energy intake $(M J / 24 h)$ from chemical analysis and from food table calculations

\begin{tabular}{lcccc}
\hline \hline $\begin{array}{l}\text { Subject } \\
\text { no. }\end{array}$ & $\begin{array}{c}\text { Gross energy } \\
\text { intake } \\
(\mathrm{MJ})\end{array}$ & $\begin{array}{c}\text { Metabolizable } \\
\text { energy (ME) } \\
\text { intake (MJ) }\end{array}$ & $\begin{array}{c}\text { Calculated } \\
\text { energy intake } \\
(\mathbf{M J})\end{array}$ & $\begin{array}{c}\text { ME: BMR } \\
\text { (MJ) }\end{array}$ \\
\hline 1 & 13.24 & 12.39 & 12.94 & 1.96 \\
2 & 9.77 & 9.09 & 9.06 & 1.95 \\
3 & 11.62 & 10.65 & 11.18 & 1.55 \\
4 & 8.74 & 7.89 & 8.29 & 1.45 \\
5 & 10.65 & 9.87 & 10.28 & 1.40 \\
6 & 7.98 & 7.09 & 7.42 & 1.37 \\
Mean (SE) & $10.34(0.72)$ & $9.50(0.71)$ & $9.86(0.75)$ & $1.61(0.11)$ \\
\hline
\end{tabular}

BMR, basal metabolic rate.

(SE 4) $\mathrm{mmol} / \mathrm{d}$ and mean analysed intake 67 (SE 4) $\mathrm{mmol} / \mathrm{d}$ (difference 6 (SE 1) $\mathrm{mmol} / \mathrm{d}$, $P<0.002$ ). There was no significant difference between analysed and calculated values of dietary intake of $\mathrm{N}$ (difference $0 \cdot 24$ (SE $0 \cdot 1) \mathrm{g} \mathrm{N} / \mathrm{d}$ ).

All subjects except no. 6 completed the training schedule; subjects nos. 1 and 2 jogging for 40 min every day by weeks 8 and 9 , and subjects nos. 3-5 jogging for $1 \mathrm{~h} / \mathrm{d}, 5 \mathrm{~d} /$ week. Subject no. 6 completed 7 weeks of training but in the last fortnight of the study did not wish to continue with her diet, the second assessment of energy expenditure using doublylabelled water, and the third $\mathrm{N}$ balance and activity-diary assessment. The study was, therefore, discontinued but $\mathrm{BMR}$, HDL-cholesterol and $V_{\mathrm{O}_{2} \max }$ measurements were obtained at the end of week 7 . Knee and ankle problems developed at weeks 4 and 6 in subjects nos. 1 and 2, and in week 8 in subject no. 4, but recovered after 1 week of bicycle exercise instead of jogging. The average speed of timed runs over measured distances was 9.0 (SE 0.6$) \mathrm{km} / \mathrm{h}$ in the women, and 13.2 (SE 0.1$) \mathrm{km} / \mathrm{h}$ in the men in weeks 8 and 9 . Training was carried out in the evenings after work by subjects nos. 1 and 2 , and in the mornings before work by subjects nos. 3-6.

\section{Activity levels and total energy expenditure}

Table 4 shows that the amount of time spent running, walking and sport had increased by weeks 8-9 to a total of 131 (SE 16) min compared with 15 (SE 2) min in the control period for the five subjects for whom complete series of values are available. About $3 \mathrm{~h} / \mathrm{d}$ more time was spent sitting in the control period than in the high-activity period (Table 4). By weeks 8-9, about $52 \mathrm{~min}$ were spent running on training days $(37 \mathrm{~min}$ if averaged over $7 \mathrm{~d})$ in subjects nos. 1, 2, 3 and 5. The values for all six subjects in the control and activity (weeks 2-4) periods were similar to those for the five subjects in the same periods (Table 4).

Values for the rate-constants $\left(K_{\mathrm{d}}, K_{\mathrm{o}}\right)$ and volumes $\left(\mathrm{V}_{\mathrm{d}}\right.$ and $\left.\mathrm{V}_{\mathrm{o}}\right)$ from the doubly-labelled water method with the standard errors of the estimates are shown in Table 5. Standard errors were rather greater for subject no. 4 than for other subjects, possibly due to leg injuries in the high-activity period, although there was no obvious cause in the low-activity period.

Table 6 shows the energy expenditure values for the last 2 weeks of the control period and weeks $8-9$ of the high-activity period, when energy expenditure had increased by $28 \%$ $(P<0.05)$. The subjects were overfed by $3 \%$ in the control period (ratio, TEE: energy intake 0.97 (SE 0.04)), but by weeks 8-9 of the high-activity period energy expenditure exceeded intake by $20 \%$. The ratio, TEE: BMR, was 1.58 (SE 0.04 ) in the control period and 1.99 (SE $0 \cdot 13$ ) in the last 2 weeks of the high-activity period. 
Metabolic rate and exercise

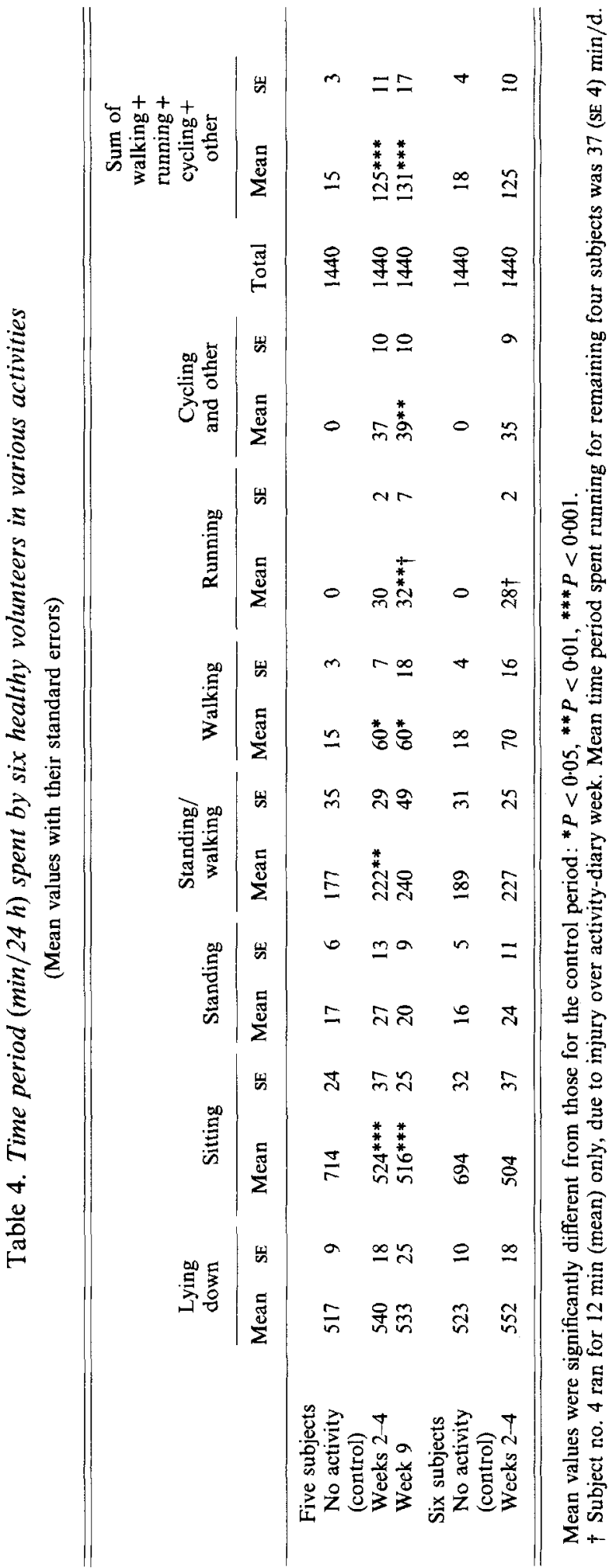




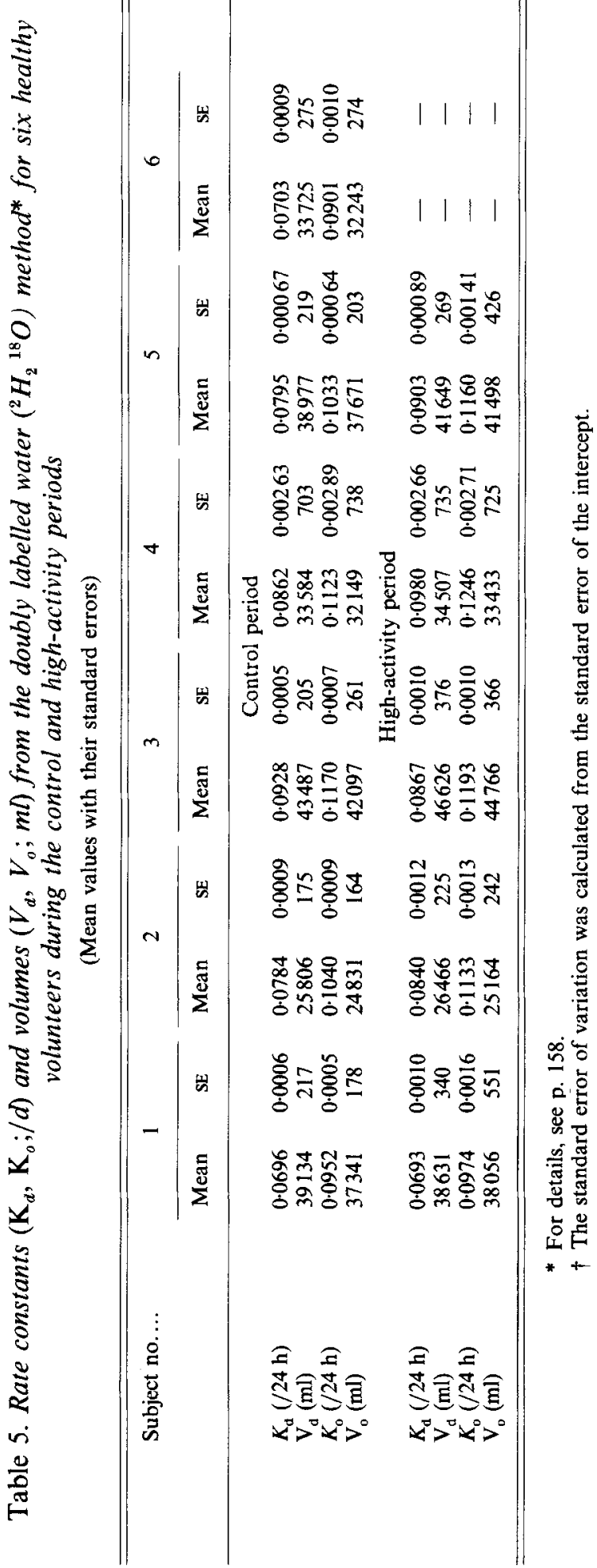


Metabolic rate and exercise

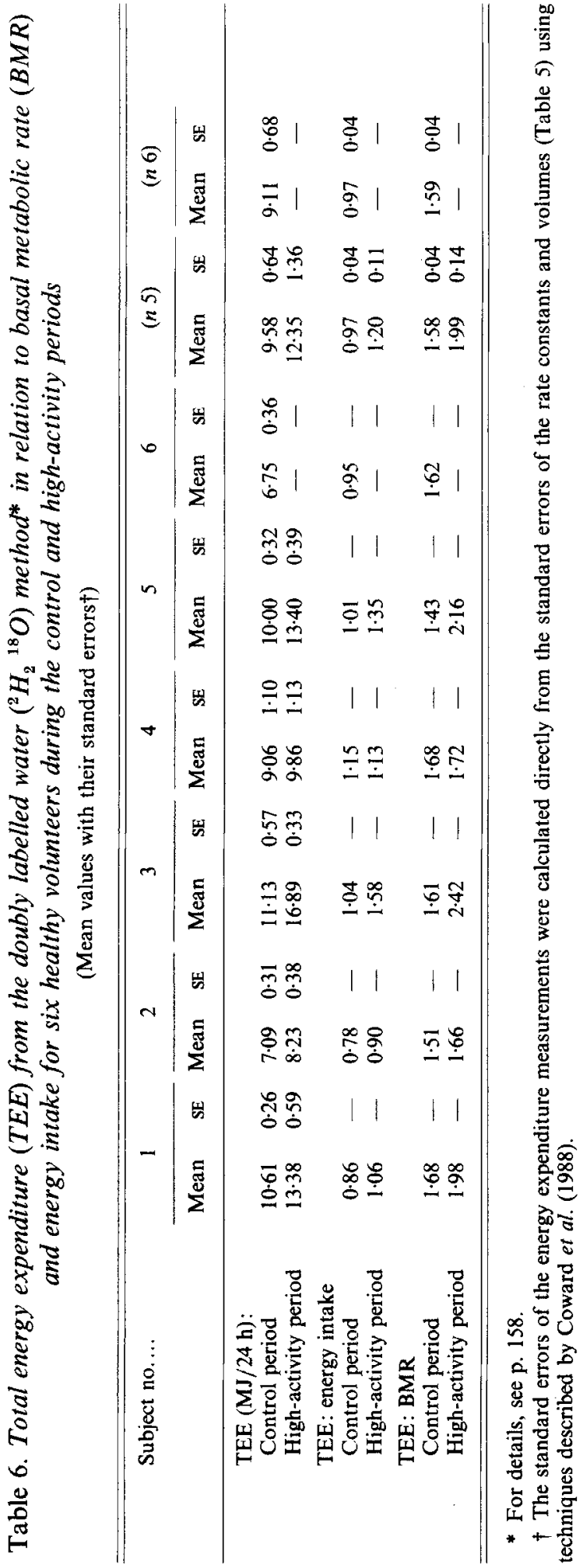




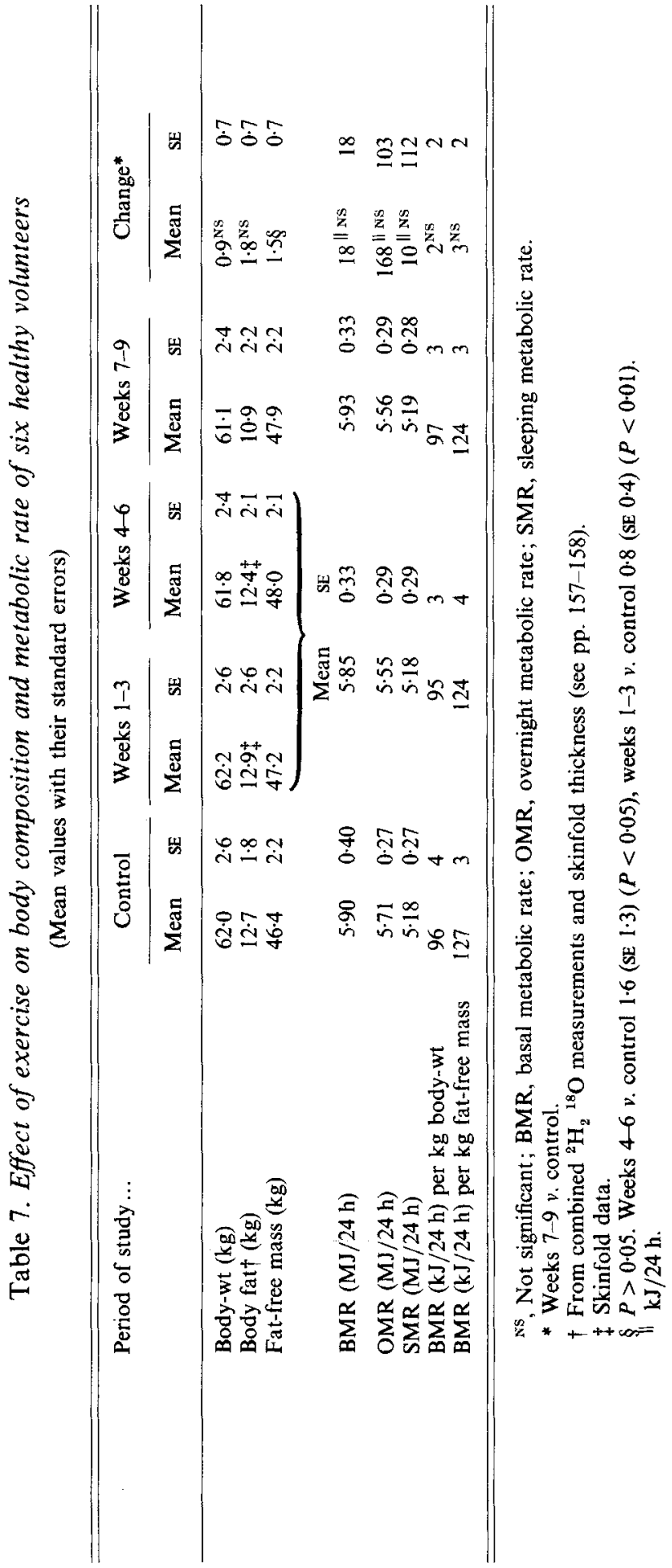


(a)

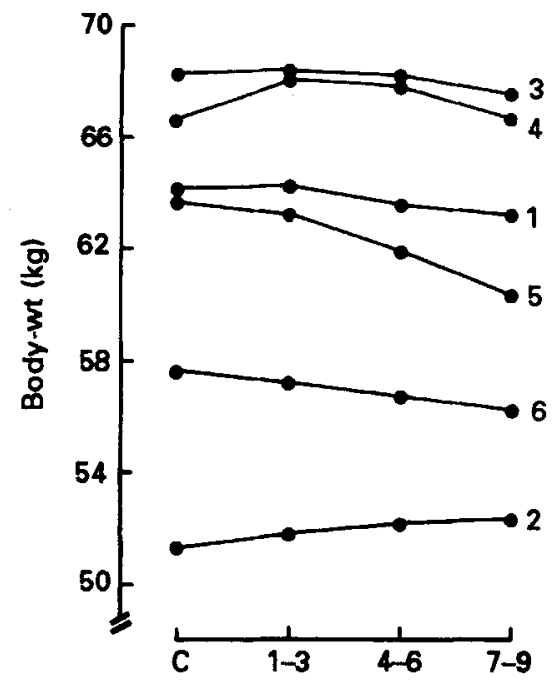

(c)

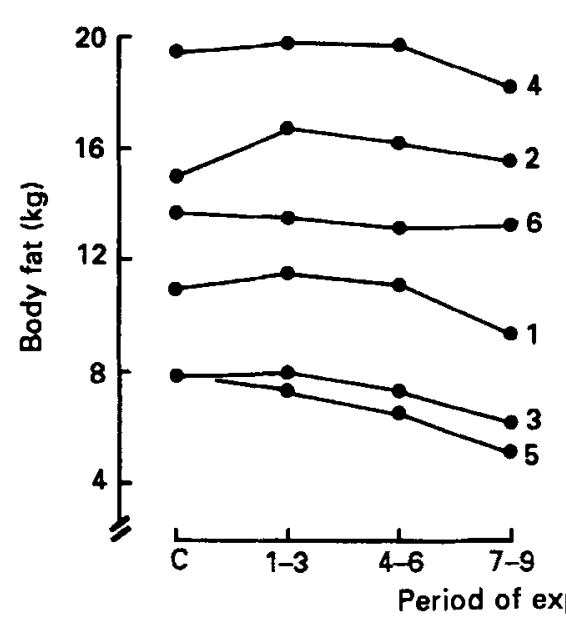

(b)

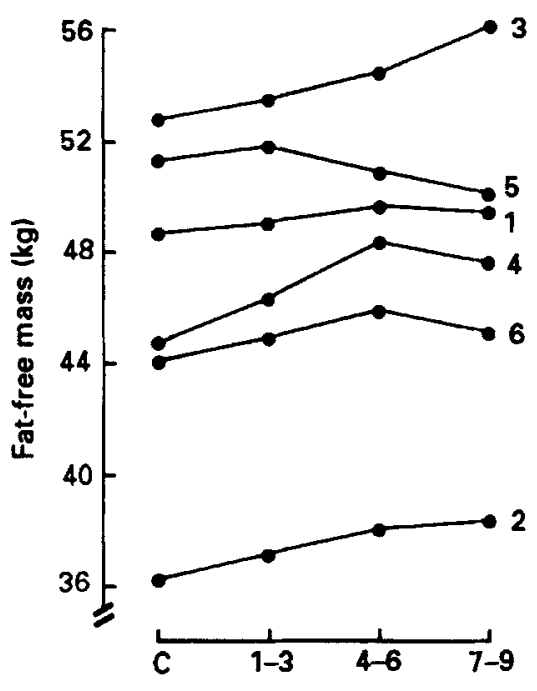

$(d)$

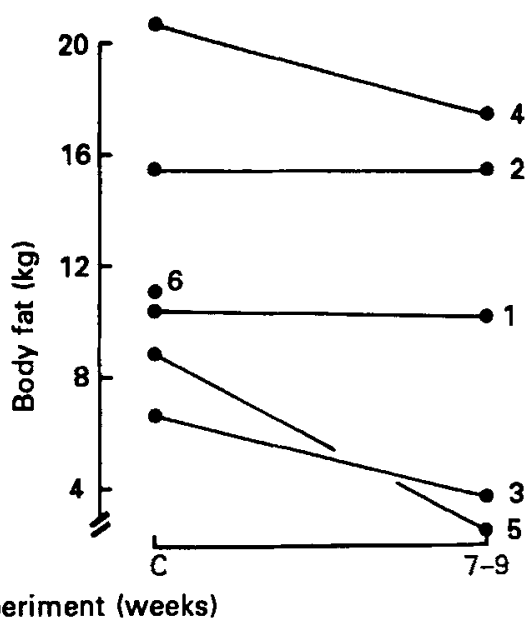

Fig. 1.(a) Body-weight, (b) fat-free mass from ${ }^{40} \mathrm{~K}$ counting, (c) body fat from the sum of skinfold thicknesses, and $(d)$ body fat from ${ }^{2} \mathrm{H}_{2} \mathrm{O}$ dilution in the six individual healthy volunteers studied. For details of various procedures, see pp. 157-158. C, control.

\section{Body-weight and composition}

There were no significant changes in body-weight over the course of the study (Table 7), two subjects gaining weight and four losing it (Fig. 1).

According to skinfold-thickness measurements, subject no. 2 gained a small amount of fat, whereas the other subjects lost fat (Fig. 1). Subjects nos. 3, 4 and 5 also lost fat, as determined by ${ }^{2} \mathrm{H}_{2} \mathrm{O}$ dilution, with no obvious changes in subjects nos.1 and 2 (Fig. 1). Body fat assessed from ${ }^{2} \mathrm{H}_{2} \mathrm{O}$ dilution was not significantly different from that assessed by skinfold thicknesses (difference 0.51 (SE 0.55) kg, $t 0.65, n$ 10), and Table 7 shows the averages of the two determinations for subjects nos. 1-5, and of the skinfold assessments 
(a)

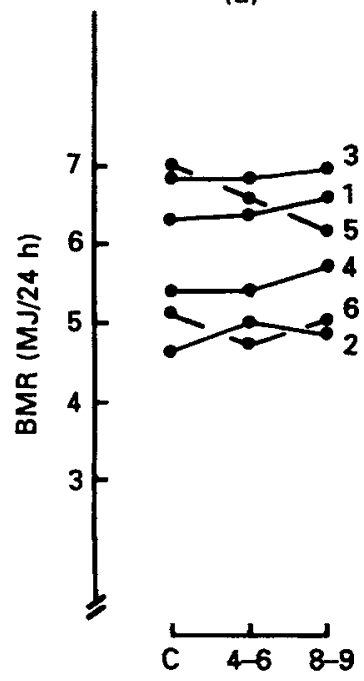

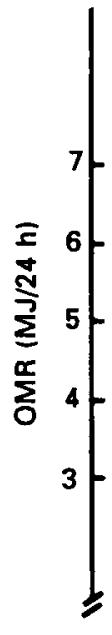

(b)
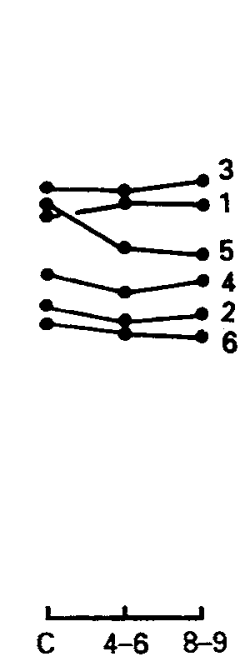

(c)

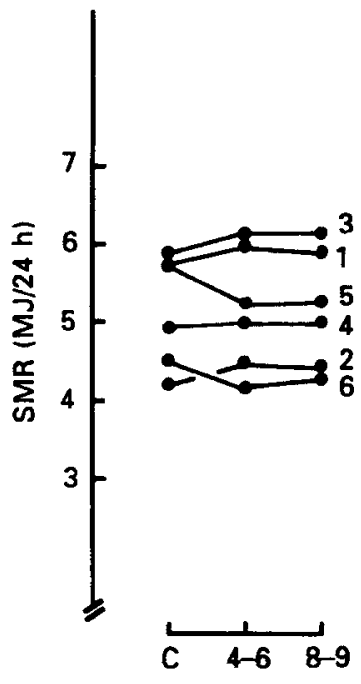

Period of experiment (weeks)

Fig. 2. Metabolic rate $(\mathrm{MJ} / 24 \mathrm{~h})$ in the six individual healthy volunteers studied. (a) Basal metabolic rate (BMR), (b) overnight metabolic rate (OMR), (c) sleeping metabolic rate (SMR). For details of procedures, see pp. 157-158. C, control.

alone in subject no. 6 for the control weeks and weeks 7-9. The average change of 1.8 (SE 0.7) $\mathrm{kg}$ was not significant.

Fat-free mass estimated from ${ }^{40} \mathrm{~K}$ counting apparently increased significantly by 0.8

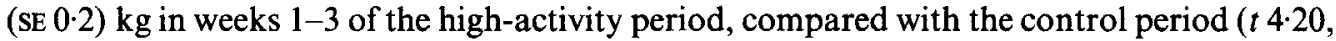
$P<0.01$ ) (Table 7). By weeks 4-6, fat-free mass continued to be significantly greater than that in the control period, but the average in the last 3 weeks, weeks $7-9$, was no greater than in the control period.

Body composition values from these methods were not consistent, since there was a 2-3 kg difference between total body-weight, and the sum of body fat and fat-free mass (Table 7).

\section{$B M R, O M R$ and $S M R$}

Table 7 shows that there were no significant changes in BMR, expressed on an absolute basis, per $\mathrm{kg}$ body-weight, or per $\mathrm{kg}$ fat-free mass. There were also no significant changes in OMR or SMR. Fig. 2 shows the individual values for OMR, SMR and BMR.

\section{$N$ and $K$ balances}

Three urine collections contained less than $90 \%$ PABA marker and were not analysed. The remaining 116 complete $24 \mathrm{~h}$ urine samples contained an average of 99.0 (SE 1.8) \% PABA marker in the control, 98.2 (SE 1.2) \% in weeks $2-4$, and 97.6 (SE 0.6) \% in week 9. Faecal collections contained 99.4 (SE 0.2 ) \% of markers given and were all complete.

There was no change in marker-corrected faecal $\mathrm{N}$ output throughout the whole study (Table 8). However, urine $\mathrm{N}$ significantly increased in weeks $8-9$ compared with the control period (Table 8$)$, due to an increase in urea output $(P<0.01$, Table 8$)$. There were no changes in creatinine output (Table 8).

$\mathrm{N}$ balance was positive in the control period $(+1.07$ (SE 0.19$) \mathrm{g} / \mathrm{d}, n 5$, skin-corrected 
Metabolic rate and exercise

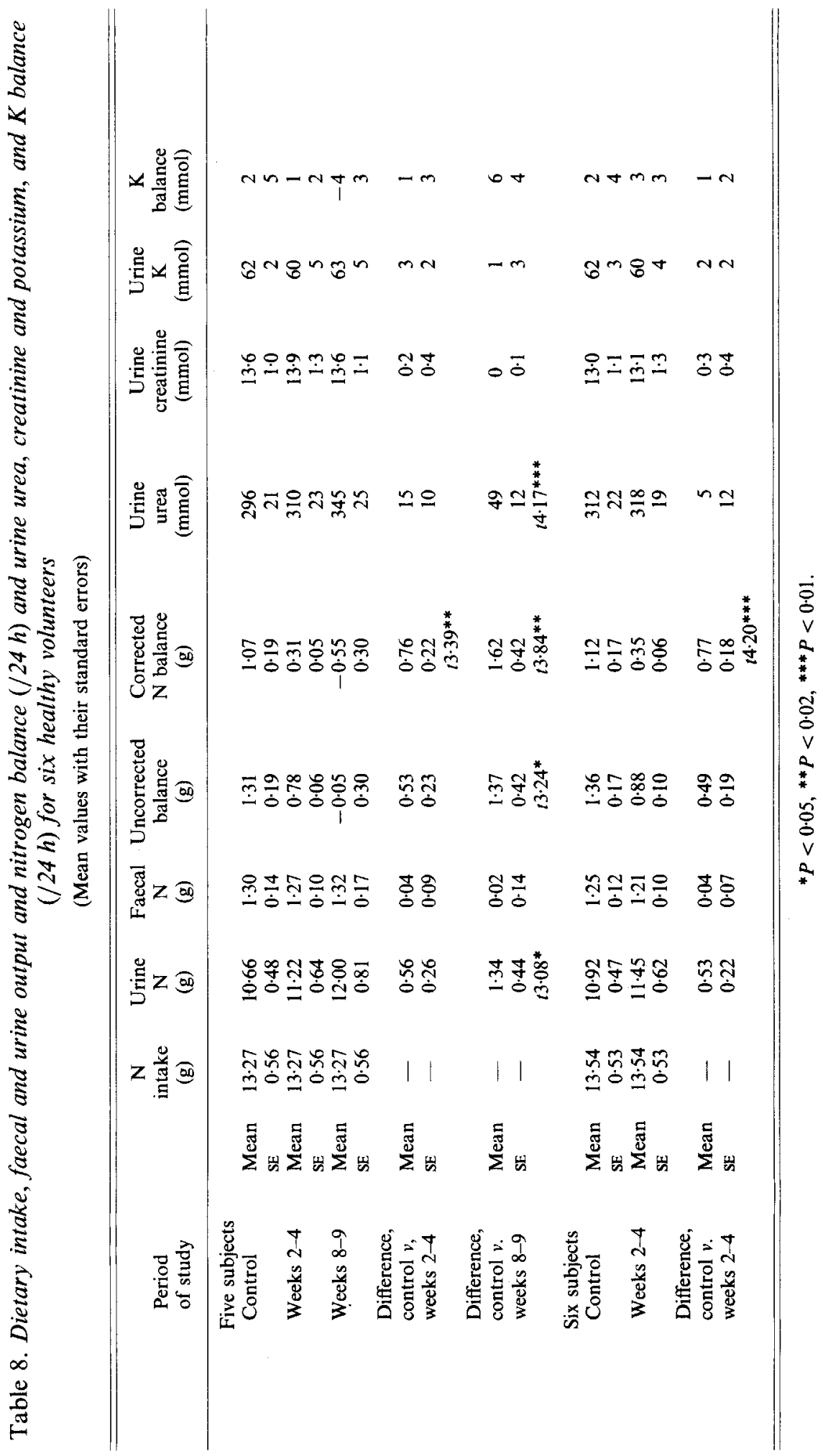




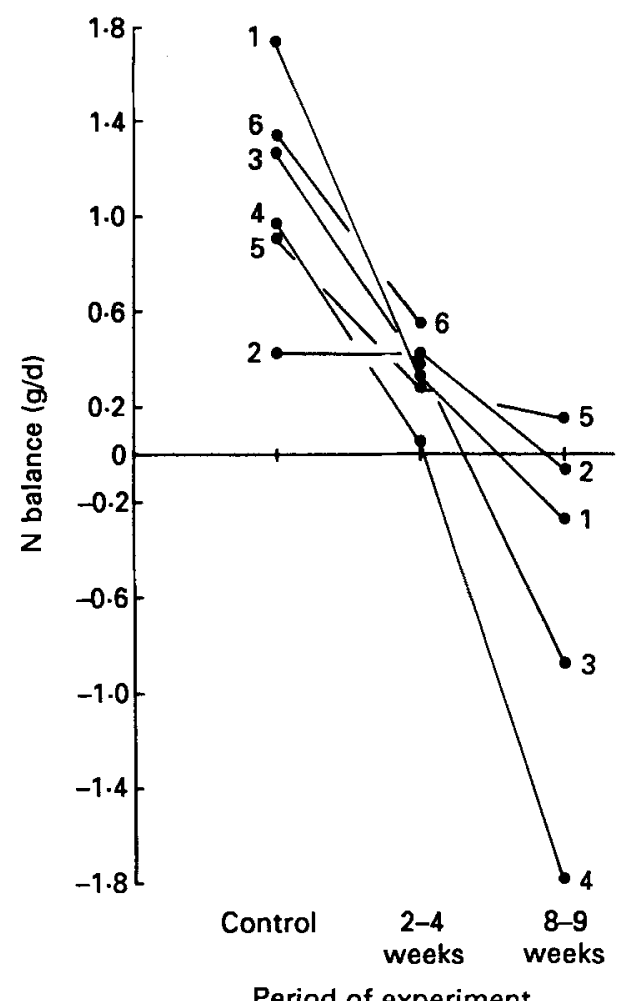

Fig. 3. Nitrogen balance ( $\mathrm{g} \mathrm{N} / \mathrm{d}$ ) for the six healthy volunteers studied. For details of procedures, see pp. $157-158$.

values, Table 8 ), but had become negative by weeks $8-9(-0.55$ (SD 0.30$) \mathrm{g} / \mathrm{d}, n 5$, skincorrected values, Table 8$)$. This difference was significant $(P<0.02) . \mathrm{N}$ balance was also significantly less positive in weeks $2-4$ compared with the control period $(P<0.02$, Table 8). Fig. 3 shows the individual values, corrected for skin losses.

There were no changes in $\mathrm{K}$ balance during the study (Table 8 ), using the analytical dietary intakes corrected for consumption of instant coffee (5 (SE 2) $\mathrm{mmol} / \mathrm{d}$ ), and faecal and urinary excretion. Mean marker-corrected faecal $\mathrm{K}$ excretion was 8 (SE 1) $\mathrm{mmol} / \mathrm{d}$, range $5-13 \mathrm{mmol} / \mathrm{d}$.

\section{Fitness}

$V_{\mathrm{O}_{2} \text { max }}$ increased significantly from 2.4 (SE 0.2$) \mathrm{l} / \mathrm{min}$ at the end of the control period to 3.1 (SE 0.3 ) $1 / \mathrm{min}$ at the end of the activity period (difference 0.7 (SE 0.2 ) $1, P<0.05$, Fig. 4). Heart rate at the standard step test also declined $(P<0.02)$ (Table 9), as did resting heart rate, from 56 (SE 2) beats/min in the control, to 50 (SE 2) beats/min during weeks 7-9 of the activity period (difference 5.4 (SE 0.8 ), $P<0.002$ ). HDL-cholesterol also significantly increased, by $0.5 \mathrm{mmol} / \mathrm{l}$ (Table 8 ). There was no change in resting blood pressure (Table 9) nor in total cholesterol (control $5 \cdot 0$ (SE 0.4) $\mathrm{mmol} / \mathrm{l}$, week 9, $5 \cdot 1$ (SE 0.1) mmol/l).

\section{DISCUSSION}

The amount of exercise achieved at the end of the present study was the maximum recommended for developing and maintaining fitness in healthy adults (American College 


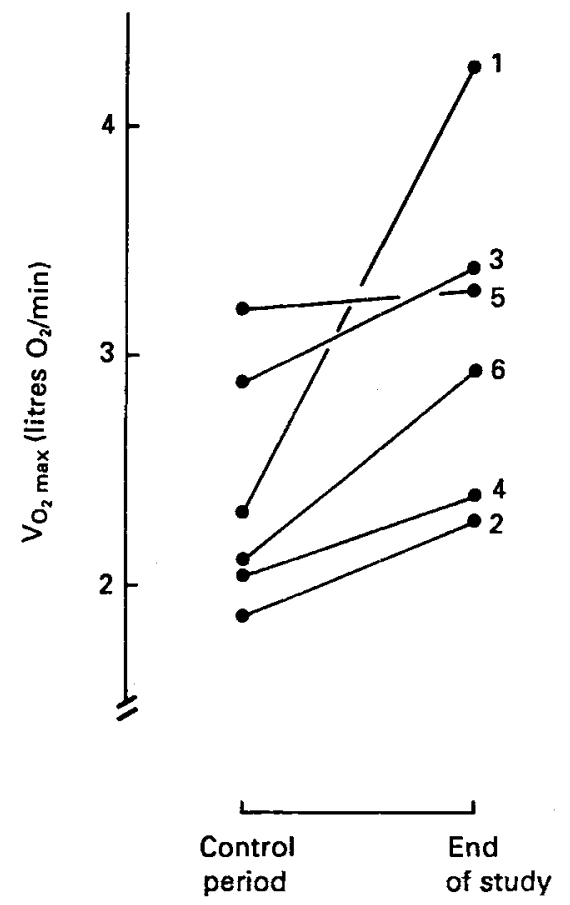

Fig. 4. Maximum oxygen consumption ( $V_{\mathrm{o}_{2} \max }$; litres oxygen $/ \mathrm{min}$ ) determined at the end of the control period and end of the study in the six healthy volunteers studied. For details of procedures, see pp. 157-158.

of Sports Medicine, 1978), and in excess of that advocated for weight loss by exercise alone (Cannon \& Einzig, 1983). Throughout the course of the study the subjects became fitter, with a $30 \%$ increase in $V_{\mathrm{O}_{2} \max }$, and a $15-20 \%$ decrease in heart rate when performing a standard step test. Heart rate when resting declined by $10 \%$, and daily energy expenditure increased by $30 \%$. HDL-cholesterol levels in serum increased by $45 \%$. All these changes would be expected to occur with increased physical exercise.

The diet was maintained at a standard constant level throughout the study. When intake is compared with expenditure, the subjects were overfed by $3 \%$ in the control period when they were leading sedentary lives. By the final $14 \mathrm{~d}$, however, they were in a negative energy balance of $-20 \%$. It was intended also to assess energy expenditure in the middle phases of the study, but due to an international shortage of ${ }^{18} \mathrm{O}$ this was not possible.

There were no significant changes in body-weight overall, but towards the end of the study the subjects were in negative energy balance which is well known to incur loss of both fat and fat-free mass. The negative $N$ balance at this time was marked ( $-0.55(\mathrm{SE} 0.30) \mathrm{g} / \mathrm{d})$, but even so would be equivalent to a loss of only approximately $100 \mathrm{~g}$ fat-free mass/ week, assuming fat-free mass contains $34 \mathrm{~g} \mathrm{~N} / \mathrm{kg}$ (Diem \& Lentner, 1970). This small change in body composition would not be detectable by the methods used in the present study. By this time, no further gain in fat-free mass had been registered by ${ }^{40} \mathrm{~K}$ counting, although skinfold measurements and ${ }^{2} \mathrm{H}_{2} \mathrm{O}$ dilution suggested a loss of body fat (Fig. 1). There was, however, poor agreement between the methods used for body composition assessment in the present study, and total body-weight (Table 7).

Rates of amino acid oxidation and gluconeogenesis are increased during exercise (Dohm et al. 1977; Dohm \& Newsholme, 1983), and the negative $\mathrm{N}$ balance measured in the last 


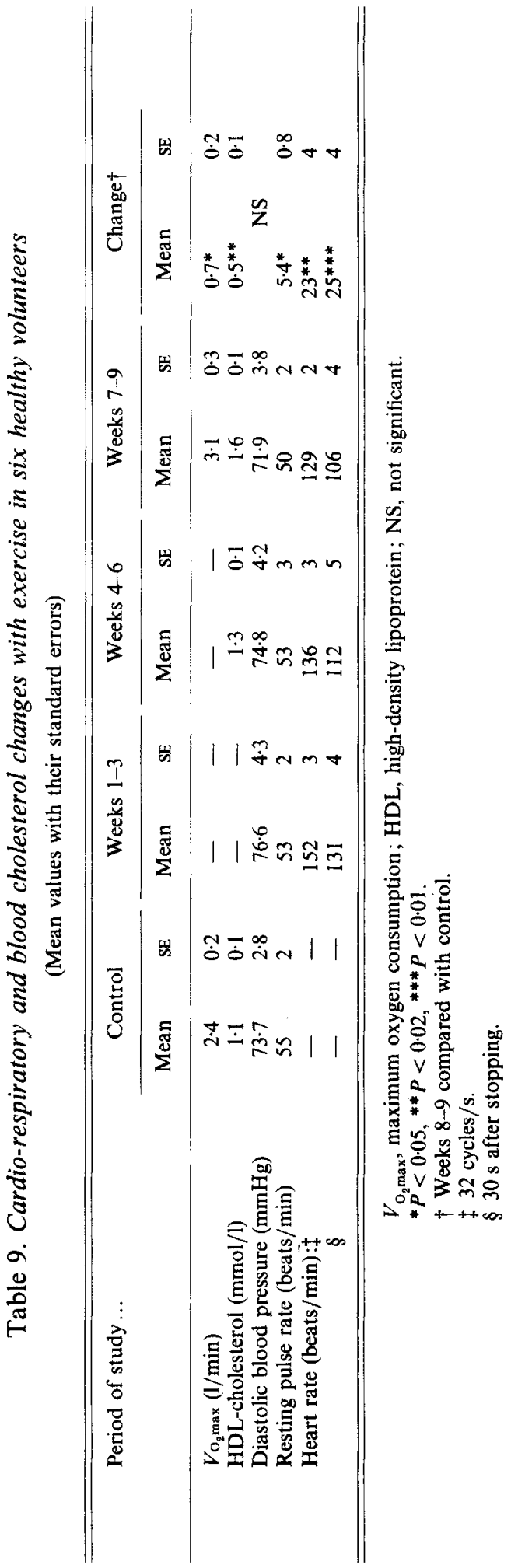


week of the present study might have been a reflection of increased requirements for protein. However, total protein breakdown is only estimated to account for less than $5 \%$ of TEE during exercise (Calles-Escandon et al. 1984), and exercise does not lead to an increase in urinary $\mathrm{N}$ excretion if subjects are in energy balance (Todd et al. 1984). This is in contrast to conditions where subjects are in negative energy balance, as occurred in the last phase of the present study, when $\mathrm{N}$ loss is a general finding due to loss of body fat and fat-free mass. In the present study, however, there was no evidence of a mitigating effect of exercise on $\mathrm{N}$ losses, as has been reported elsewhere (Todd et al. 1984).

It has been suggested that metabolic rate is elevated after exercise. This adventitious addition to energy loss could be potentially important for both the prevention and the treatment of obesity. A mechanism for this elevation has been suggested (Newsholme, 1980). However, increased $\mathrm{O}_{2}$ consumption following exercise does not occur as a general rule. Pacy et al. (1985) and Steinhaus (1983) were unable to find support for its occurrence from a review of the early literature, mostly because of problems in interpreting poorly controlled experiments. Later studies have yielded conflicting results, even in wellcontrolled short-term experiments. Maehlum et al (1986), for example, exercised eight healthy normal-weight subjects for $80 \mathrm{~min}$ at $70 \% V_{\mathrm{o}_{2} \max }$, and found significantly increased levels of $\mathrm{O}_{2}$ consumption in the $12 \mathrm{~h}$ period after exercise compared with control values. Freedman-Akabas et al. (1985), however, exercised twenty-three normal-weight subjects for $20 \mathrm{~min}$, and were unable to detect a significant difference in post-exercise $\mathrm{O}_{2}$ consumption compared with control values. In this latter study, $\mathrm{O}_{2}$ consumption returned to baseline values within $40 \mathrm{~min}$ of either intense or moderate exercise. Dallosso \& James (1982) found that a 30 min period of cycling immediately before bed had no significant effect on total $8 \mathrm{~h}$ night-time energy expenditure in normal-weight subjects. Pacy et al. (1985) also could not find a prolonged thermogenic effect following four 20 min periods of exercise in lean individuals. Bielinski et al. (1985) found that morning resting metabolic rate (RMR) measured after exercise was significantly higher than when measured after no exercise, but the order of presentation of exercise in this study was not randomized.

Results of studies which have attempted to assess the benefits of exercise in hastening loss of body fat in the obese given an energy-restricted diet are also inconsistent. In one recent study, for example, a small increase in RMR (amounting to $250-335 \mathrm{~kJ}(60-80 \mathrm{kcal}) / \mathrm{d}$ ) was reported in eight free-living obese subjects following as exercise training programme (Tremblay et al. 1986). However, in the study of van Dale et al. (1987) RMR expressed per $\mathrm{kg}$ fat-free mass decreased in obese subjects following a combined programme of diet and exercise, although to a lesser extent than in the group treated by diet alone. Hensen et al. (1987) were unable to reverse the dietary-induced depression of resting energy expenditure in obese subjects by exercise. In the majority of published studies, there are no significant differences in the amount of body fat lost in obese patients treated by diet alone, or by diet and exercise (van Dale et al. 1987).

The findings of the present study, where diet was closely controlled at a constant level throughout the entire period, suggest that, if there is an enhanced effect of exercise on $\mathrm{O}_{2}$ consumption the effect is short-lived, less than $24 \mathrm{~h}$. Despite marked changes in energy balance and activity levels, there was no increase in OMR, SMR or BMR measured up to $24 \mathrm{~h}$ after exercise, when expressed on either an absolute or a per $\mathrm{kg}$ body-weight basis.

The absence of an increase in BMR does not suggest that adequate levels of exercise are unimportant in the maintenance of cardiovascular fitness and prevention of obesity, particularly in urbanized countries such as Britain where activity levels are now very low (Prentice et al. 1985). Nevertheless, levels of exercise sufficient to cause a significant deficit in energy balance without dieting are not without orthopaedic risk in the treatment of 
obesity, and, as with dieting, require a high level of patient motivation for success. In the case of exercise, failure to adhere to regimens is as big a problem as it is with slimming diets (Gale et al. 1984). In addition, the results of the present study do not support the suggestion that there is a sustained enhanced effect of exercise on the metabolic rate over and above the energy cost of the activity itself.

The volunteers who completed this study are thanked for their enthusiastic and conscientious participation. Our thanks are also due to Dr S. Olpin for the cholesterol analyses, Dr N. Norgan for advice on training and heart rate measurements, $\mathrm{Dr} \mathrm{T}$. Cole for statistical assistance, and Mr K. Szaz for help with the total body potassium measurements. Miss M. Fitzpatrick of the Department of Respiratory Physiology, Papworth Hospital is thanked for the $V_{\mathrm{O}_{2} \max }$ determination. Mrs E. Collard and Mrs S. Runswick are thanked for technical assistance, and Professor W. P. T. James kindly loaned some ${ }^{2} \mathrm{H}_{2}{ }^{18} \mathrm{O}$ in the final stages of the study.

\section{REFERENCES}

American College of Sports Medicine (1978). The recommended quality and quantity of exercise for developing and maintaining fitness in healthy adults Medicine and Science in Sports 10 , vii-x.

Barrie, A. \& Coward, W. A. (1985). A rapid analytical technique for the determination of energy expenditure by the doubly labelled water method. Biomedical Mass Spectrometry 12, 535-541.

Bielinski, R., Schultz, Y. \& Jequier, E. (1985). Energy metabolism during the post exercise recovery in man. American Journal of Clinical Nutrition 42, 69-82.

Bingham, S. \& Cummings, J. H. (1983). The use of 4 amino benzoic acid as a marker to validate the completeness of $24 \mathrm{~h}$ urine collections in man. Clinical Science 64, 629 635.

Bingham, S. \& Cummings, J. H. (1985). Urine nitrogen as an independent validatory measure of dietary intake. American Journal of Clinical Nutrition 42, 1276-1289.

Black, A. E., Prentice, A. M. \& Coward, W. A. (1986). Use of food quotients to predict respiratory quotients for the doubly labelled water method. Human Nutrition: Clinical Nutrition 40C, 381-391.

Bruce, R. A. \& McDonough, J. R. (1969). Stress testing in screening and cardiovascular disease. Bulletin of the New York Academy of Medicine 45, 1288-1305.

Calles-Escandon, J., Cunningman, J. J., Snyder, P., Jacob, R., Huszar, G., Loke, J. \& Felig, P. (1984). Urea, creatinine and 3-methyl histidine in exercise. American Journal of Physiology 246, E334-E338.

Cannon, G. \& Einzig, H. (1983). Dieting Makes You Fat. London: Century Publishing.

Coward, W. A. \& Prentice, A. M. (1985). Isotope method for the measurement of carbon dioxide production in man. American Journal of Clinical Nutrition 41, 659-661.

Coward, W. A., Prentice, A. M., Murgatroyd, P. R., Cole, T. J., Sawyer, M. B., Goldberg, G. R., Halliday, D. \& Macnamara, J. P. (1985). Measurements of $\mathrm{CO}_{2}$ and water production rates in man using ${ }^{2} \mathrm{H}_{2}{ }^{18} \mathrm{O}$. In Human Energy Metabolism: Physical Activity and Energy Expenditure Measurements in Epidemiology Research Based upon Direct and Indirect Calorimetry, Euronut Report no. 5, pp. 126-128 [A. J. H. Van Es, editor]. Den Haag: CIP-gegevens Koninklijke Bibliotheek.

Coward, W. A., Roberts, S. B. \& Cole, T. J. (1988). Theoretical and practical considerations in the doubly labelled water $\left({ }^{2} \mathrm{H}_{2}{ }^{18} \mathrm{O}\right)$ method for the measurement of carbon dioxide production rate in man. European Journal of Clinical Nutrition 42, 207-212.

Coward, W. A., Roberts, S. B., Prentice, A. M. \& Lucas, A. (1986). The ${ }^{2} \mathrm{H}_{2}{ }^{18} \mathrm{O}$ method for energy expenditure measurements. In Clinical Nutrition and Metabolic Research. Proceedings of the 7th Congress of the European Society of Parenteral - Enteral Nutrition (ESPEN), Munich 1985, pp. 169-177 [C. J. Dietze, A. Grumert, G. Kleinberger and G. Wolfram, editors]. Basel: Karger.

Cummings, J. H., Jenkins, D. J. A. \& Wiggins, H. S. (1976). Measurement of mean transit time of dietary residue through the human gut. Gut 17, 210-218.

Dallosso, H. \& James, W. P. T. (1982). Dietary thermogenesis and exercise. Proceedings of the Nutrition Society 41, 35A.

Diem, K. \& Lentner, C. (1970). Documenta Geigy Scientific Tables. Basle, Switzerland: Ciba Geigy Ltd.

Dohm, G. L., Hecker, A. L., Brown, W. E., Klain, G. J., Puente, F. R., Askew, E. W. \& Beecher, G. R. (1977). Adaptation of protein metabolism to endurance training. Biochemical Journal 164, 705-708.

Dohm, G. L. \& Newsholme, E. A (1983). Metabolic control of hepatic gluconeogenesis during exercise. Biochemical Journal 212, 633-639.

Durnin, J. V. G. A. \& Womersley, J. (1974). Body fat assessed from total body density and skinfold thickness. British Journal of Nutrition 32, 77-97. 
Edwards, H. T., Thorndike, A. \& Dill, D. B. (1935). The energy requirements in strenuous muscular exercise. New England Journal of Medicine 213, 532-535.

Feldman, H. A. (1977). A numerical method for fitting compartmental models directly to tracer data. American Journal of Physiology 233, R1-R7.

Forbes, G. B. \& Bruining, G. J. (1976). Urinary creatinine excretion and lean body mass. American Journal of Clinical Nutrition 29, 1359-1366.

Freedman-Akabas, S., Colt, E., Kissileff, H. \& Pi-Sunyer, F. (1985). Exercise-induced thermogenesis. American Journal of Clinical Nutrition 41, 545-549.

Gale, J. B., Eckhoff, W. T., Mogel, S. F. \& Rodnick, J. E. (1984). Exercise program adherence. Medicine and Science in Sports and Exercise 16, 544-549.

Halliday, D. R. \& Miller, A. G. (1977). Precise measurement of total body water using trace quantities of deuterium oxide. Biomedical Mass Spectrometry 4, 82-87.

Hensen, L. C., Poole, D. C., Donahoe, C. P. \& Heber, D. (1987). Exercise and resting energy expenditure. American Journal of Clinical Nutrition 46, 893-899.

Lopes-Virella, M. F., Stone, P., Ellis, S. \& Colwell, J. A. (1977). Cholesterol determination in HDL separated by 3 different methods. Clinical Chemistry 23, 882-884.

Maehlum, S., Grandmontagne, M., Newsholme, E. \& Sejersted, O. (1986). Magnitude and duration of excess post exercise oxygen consumption in healthy young subjects. Metabolism 35, 425-429.

Margaria, R., Edwards, H. T. \& Dill, D. B. (1933). The possible mechanisms of paying the oxygen debt in muscular contraction. American Journal of Physiology 106, 689-715.

Murgatroyd, P. R., Prentice, A. M., Davies, H. L., Goldberg, G. R. \& Cole, T. J. (1985). Whole body calorimetry of lactating women. In Human Energy Metabolism: Physical Activity and Energy Expenditure Measurements in Epidemiology Research Based upon Direct and Indirect Calorimetry, Euronut Report no. 5, pp. 49-50 [A. J. H. Van Es, editor]. Den Haag: CIP gegevens Koninklijke Bibliotheek.

Newsholme, E. A. (1980). A possible metabolic basis for the control of body weight. New England Journal of Medicine 302, 400-405.

Pacy, P. J., Barton, N., Webster, J. D. \& Garrow, J. S. (1985). The energy cost of aerobic exercise in fed and fasted normal subjects. American Journal of Clinical Nutrition 42, 764-768.

Passmore, R. \& Eastwood, M. A. (1986). Davidson \& Passmore's Human Nutrition and Dietetics, 8th ed. Edinburgh: Churchill Livingstone.

Passmore, R. \& Johnson, R. E. (1960). Some metabolic changes following prolonged moderate exercise. Metabolism 9, 452-455.

Paul, A. A. \& Southgate, D. A. T. (1978), McCance \& Widdowson's The Composition of Foods, 4th ed. London: H.M. Stationery Office.

Prentice, A. M., Coward, W. A., Davies, H. L., Murgatroyd, P. R., Black, A. E., Goldberg, G. R., Ashford, J., Sawyer, M. \& Whitehead, R. G. (1985). Unexpectedly low levels of energy expenditure in healthy women. Lancet ii, 1419-1422.

Prentice, A. M., Goldberg, G. T., Murgatroyd, P. R., Davies, H. L. \& Scott, W. (1989). Variable metabolic responses in human pregnancy assessed by whole body calorimetry. British Journal of Nutrition (In the Press).

Slikers, K. A. (1977). Enzyme-linked assays for cholesterol. Critical Reviews in Clinical Laboratory Science 8, 193-212.

Steinhaus, A. H. (1983). Chronic effects of exercise. Physiological Reviews 13, 103-147.

Todd, K. S., Butterfield, G. E. \& Calloway, D. H. (1984). Nitrogen balance and work. Journal of Nutrition 114, 2107-2118.

Tremblay, A., Fontaine, E., Pohlman, E., Mitchell, D., Perron, L. \& Bouchard, C. (1986). The effect of exercise on RMR in lean and moderately obese individuals. International Journal of Obesity 10, $511-517$.

van Dale, D., Saris, W. H. M., Schofflen, P. F. M. \& Ten Hoor, F. (1987). Does exercise give an additional effect in weight reduction regimes? International Journal of Obesity 11, 367-375. 